\title{
Chemical composition, antioxidant and antimicrobial activities of the essential oil of Illicium verum
}

\author{
Brahim OUTEMSAA ${ }^{1 *}$, Asmaa OUBIHI $^{1}$, Hassna JABER ${ }^{1}$, Sara HAIDA $^{2}$, Ikram KENFAOUI $^{1}$, Rachid IHAMDAN $^{3}$, Hamza \\ EL AZHARI ${ }^{4}$, Mohammed OUHSSINE ${ }^{1}$
}

\footnotetext{
1 Laboratory of Natural Resource and Sustainable Development. Department of Biology, Faculty of Science; Ibn Tofaïl University. Kenitra, Morocco.

${ }^{2}$ Laboratory of Advanced Materials and Process Engineering. Department of Chemistry, Faculty of sciences, Ibn Tofail University. Kénitra Morocco.

${ }^{3}$ Laboratory of Organic chemestry, Catalysis| and Environment. Department of Chemistry, Faculty of sciences, Ibn Tofail. University. Kénitra Morocco.

${ }^{4}$ Physical chemistry laboratory of materials, natural substances and environment (UAE / U16FST), FST Tangier, Department of chemistry - Faculty of Sciences and Technology of Tangier, Morocco.
}

\begin{abstract}
In recent years, a concern has been expressed about the impact of antibiotics and synthetic antioxidants, which are used to inhibit microbial growth and retard fat oxidation in foods. In addition, antibiotic resistance presents a serious menace to human and environmental ecosystems. This has led the food industry to use natural resources such as essential oils in the preparation of foods, this forming their sensory profile and increasing preservation time there. The objective of this work is to determine the chemical composition and evaluate the antibacterial and antioxidant activity of the essential oil of Illicium verum. The yield of essential oil extracted by hydro distillation is about $4.13 \%$. The chemical composition of the essential oil extracted from the dried fruits of Illicium verum was studied by gas chromatography coupled with mass spectrometry (GC and GC/MS). Twenty-eight constituents, representing $99.74 \%$ of the essential oil were identified. The major compounds are: trans-anethole $(83.46 \%)$, D-Limonene (4.56\%), Estragole $(3.47 \%)$ and Linalool (1.07\%). Antioxidant activity was determined by the DPPH assay. The essential oils of Illicium verum showed low antioxidant activity with IC50 $=286.19 \pm 7.4 \mathrm{mg} / \mathrm{mL}$, compared to Ascorbic acid IC $50=0.09 \pm 0.01 \mathrm{mg} / \mathrm{mL}$. The antibacterial effect of this essential oil was tested against six microorganisms, of which Staphylococcus aureus is the most sensitive with an MIC of about 1/1000 (v/v), followed by Staphylococcus epidermidis and Enterobacter cloacae with an MIC equal to 1/100 (v/v).
\end{abstract}

Key words: Illicium verum, Essential oil, chemical composition, antibacterial activity, antioxidant activity.

* Corresponding author email: ibrahimmauvitch@hotmail.com 


\section{Introduction}

Manufactures use chemical preservatives including antioxidants and antiseptic substances that slow the growth of bacteria and molds [1]. The uncontrolled use of these products constitutes a major risk to public health. The transfer of resistant bacteria to humans via the food chain and the environment constitutes one of the major routes of spread of antibiotic resistance [2], as well as the use of synthetic antioxidant molecules are responsible of potential toxicological risks [3]. Regarding those problems, medicinal plants still remain the reliable source of active compounds known by their medicinal properties [4]. These plants have been widely studied, they are generally considered as a rich source of antimicrobial and antioxidant compounds [5.6], and have considerable economic interest by belonging to the agri-food, pharmaceutical and cosmetic industries [7]. Currently, the use of essential oils is carried out on scientific and rational bases with the aim of developing new products for various medical, veterinary, agronomic and cosmetic uses [8.9.10]. Indeed, Chinese star anise (Illicium verum) is a plant distributed in the tropical and subtropical area of Asia and widely used in traditional medicine [11]. It is used in herbal medicine as well as for flavoring pharmaceutical, food and cosmetic products, and its use has a long [12]. The fruits are commonly used as a spice and pharmaceutical treatment of flatulence, spasmodic pain and colic [13]. Star anise oil is used topically to treat rheumatism and otalgia, and also used as an antiseptic [14]. In a previous study, it was documented that Illicium verum Hook exhibits antimicrobial, antifungal, antiinflammatory, ant allergic, antioxidant and anticancer effects [15]. The objective of the present study is the valorization of the essential oil of Illicium verum through, on the one hand, the evaluation of the antioxidant power and the antibacterial activity of this species, on the other hand, the determination of its chemical composition

\section{Material and methods}

\subsection{Biological material}

\subsubsection{Plant material}

Samples of Illicium Verum fruits were purchased from local herbal suppliers. The samples were washed, airdried, crushed and stored at $4{ }^{\circ} \mathrm{C}$ in the refrigerator before extraction.

\subsubsection{Bacterial strains}

Two-gram positive bacteria (Staphylococcus aureus, Staphylococcus epidermidis), four-gram negative bacteria (Enterobacter cloacae, Escherichia coli, Acinetobacter baumannii, Klebsiella pneumoniae) were used to determine their sensitivities to Illicium Verum EO (Antimicrobial activity). The selection was made based on their pathogenicity and antibiotic resistance. They are maintained by subculturing on nutrient agar favorable to their growth. The germs are maintained by subculture on nutrient agars favorable to their growth.

\subsection{Methods}

\subsubsection{Extraction technique}

The essential oil from $200 \mathrm{~g}$ of Illicium Verum fruits was obtained by steam distillation using a Clevenger type distiller (Clevenger, 1928) for $3 \mathrm{~h}$. The essential oil was recovered, after extraction, and preserved in small opaque bottles and stored at $4^{\circ} \mathrm{C}$ before use.

The oil obtained was divided into two parts.

- The first was used for chemical analysis while the second was used to study the properties of the oil;

- The second was used to study the in vitro antibacterial tests.

\subsubsection{Chromatographic analysis}

The volatile compound profile was characterized by gas chromatography (GC) (Agilent 7890A Series) coupled to mass spectrometry (MS) equipped with a multimode injector and a 123-BD11 column of dimension $15 \mathrm{~m} \times 320$ $\mu \mathrm{m} \times 0.1 \mu \mathrm{m} .4 \mu \mathrm{L}$ of the soluble extract was injected into the column by split $1 / 3$ mode using helium as carrier gas at $3 \mathrm{ml} \mathrm{min}-1$. The temperatures of the ion source and quadrupoles were 230 and $150^{\circ} \mathrm{C}$, respectively. The oven temperature program was started at $34^{\circ} \mathrm{C}$ and finished at $360^{\circ} \mathrm{C}$. $10 \mu$ Sample was solubilized in chloroform as solvent. Identification was performed using NIST 2014 MS Library.

\subsubsection{Solid-state diffusion method}

Antibacterial activity is performed using the Muller Hinton agar media diffusion method [16]. A microbial suspension with an optical density of 1 McFarland is spread on the petri dish of agar media. Filter paper discs (Whatman $\left.\mathrm{N}^{\circ} 6\right)$ sterilized in an autoclave $\left(121^{\circ} \mathrm{C}\right.$ for 20 minutes), were soaked with the essential oil to be tested, and were deposited on the surface of the seeded agar, the whole is incubated for 24 hours at a temperature of $37^{\circ} \mathrm{C}$. After incubation, the presence $\mathrm{s}$ of a circular inhibition zone around the discs denotes the susceptibility of the microorganisms to HE tested. The larger the zone of inhibition, the more sensitive the germ. Ampicillin $(10 \mu \mathrm{g})$ and penicillin $(5 \mu \mathrm{g})$ are used as positive controls.

\subsubsection{Minimum inhibitory concentration}

The minimum inhibitory concentration (MIC) is determined by the solid-state macro dilution technique [17]. The essential oil is emulsified by an agar solution at a concentration of $0.2 \%$. A volume of $1.5 \mathrm{~mL}$ of dilutions of the order of $1 / 10$ th, $1 / 25$ th, $1 / 50$ th, $1 / 100$ th, $1 / 200$ th, $1 / 300$ th and $1 / 500$ th was prepared in test tubes each containing $13.5 \mathrm{~mL}$ of Muller Hinton solid medium, so as to obtain the final concentrations of $1 / 100,1 / 250,1 / 500$, $1 / 1000,1 / 2000,1 / 3000$ and $1 / 5000(\mathrm{v} / \mathrm{v})$. The contents of each tube are immediately poured into a sterile Petri dish

\footnotetext{
* Corresponding author: ibrahimmauvitch@hotmail.com
} 
after shaking for 15 seconds. Controls, containing culture medium only.

Inoculation was performed by streaking with a calibrated platinum loop to collect the same volume of inoculums. Incubation was performed at $37^{\circ} \mathrm{C}$ for 24 hours. The MIC is defined from the first plate of the range free of bacterial growth. Each experiment is repeated three times.

\subsubsection{DPPH radical reduction test}

The antioxidant power of Illicium Verum essential oil was evaluated by the DPPH (1.1-diphenyl-2-picrylhydrazyl) test [18.19]. $2 \mathrm{~mL}$ of the ethanolic solution of DPPH (76 $\mu \mathrm{M})$ was mixed with $0.1 \mathrm{~mL}$ of different ethanolic concentrations of the essential oil. The mixture was stirred and then incubated in the dark at room temperature for 30 minutes. The transformation from the radical form (purple coloration) to the reduced form of DPPH (yellow coloration) was measured with a UV-Vis spectrophotometer at $527 \mathrm{~nm}$. A blank was prepared only with the ethanolic solution of DPPH. Ascorbic acid was used as the standard reference compound. The percentage of inhibition was calculated using the following formula:

$$
\% \text { of inhibition }=\frac{[(\text { Abs Blank }- \text { Abs Sample })]}{[\text { Abs Blank }]} \times 100
$$

The inhibitory concentration 50 (IC50), the concentration of the essential oil required to reduce $50 \%$ of the initial DPPH, was calculated using the lines of variation of the percentage of inhibition as a function of concentrations.

\subsection{Statistical analysis}

Data are expressed as mean values \pm standard deviation for each measurement. The statistical study is performed in Excel.

\section{Result discussions}

\subsection{Yield}

The yield is determined by calculating the weight of essential oil in relation to the weight of dry plant material made into powder and used in hydro distillation, the results were expressed as a percentage per $100 \mathrm{~g}$ of dry matter $(\mathrm{P} / \mathrm{P})$, and the yield was calculated using the formula:

$$
\text { R }=\frac{\text { Mhe }}{\text { Mvg }} \times 100
$$

- R: EO yield in (\%)

- Mho: Mass of the essential oil

- Mdp: Mass of dry plant

According to our results, the yield of essential oil obtained from star anise seeds is $4.13 \%$. However, the comparison of the calculated yield with that of the bibliography is difficult because the yield is relative and depends on several parameters such as the method and conditions of extraction, the method of drying and also the geographical origin of the species [20.21]

\subsection{Chemical composition}

The results of gas chromatography-mass spectrometry (GC and GC/MS) analysis of the essential oil of I. verum are presented in Table 1 This essential oil contains twenty-eight constituents, representing $99.74 \%$ of the essential oil were identified. The major compounds are: trans-anethole (83.46\%), D-Limonene (4.56\%), Estragole (3.47\%) and Linalool (1.07\%).

Research has shown similar results to our study, and was able to identify the same composition in aniseed star anise EO with a percentage of trans-anethole ranging from $88.5 \%$ to $92.4 \%$ [22.23.24]. This major compound is known for its biological activities, namely antioxidant and antimicrobial [25]. Other compounds found in star anise EO were D-Limonene (4.56\%), estragole, an isomer of anethole (3.47\%), and terpineol (1.70\%), all of which are known bioactive photochemical commonly found in essential oils [26.27]. The variations found in the level of chemical profile of the essential oil of I. verum, can be explained by variations in climatic conditions, harvesting period, extraction method and storage method of the essential oil [28.29.30.31]

Table 1: Chemical composition of the essential oil of Illicium verum

\begin{tabular}{|c|c|c|c|}
\hline $\mathbf{N}^{\circ}$ & Compound & $\begin{array}{c}\text { Retention } \\
\text { time (min) }\end{array}$ & $\begin{array}{c}\text { Percen } \\
\text { tage } \\
\mathbf{( \% )}\end{array}$ \\
\hline 1 & $\alpha$-Pinene & 2.06 & 0.31 \\
\hline 2 & Camphene & 2.24 & 0.04 \\
\hline 3 & Linalool 3,7-oxide & 2.71 & 0.06 \\
\hline 4 & $\beta$-Myrcene & 3.17 & 0.20 \\
\hline 5 & $\alpha-P h e l l a n d r e n e$ & 3.27 & 0.24 \\
\hline 6 & 3-Carene & 3.39 & 0.39 \\
\hline 7 & 4-Carene & 3.54 & 0.28 \\
\hline $\mathbf{8}$ & D-Limonene & $\mathbf{3 . 8 7}$ & $\mathbf{4 . 5 6}$ \\
\hline 9 & $\beta$-Ocimene & 4.38 & 0.06 \\
\hline 10 & $\gamma$-Terpinene & 4.48 & 0.19 \\
\hline 11 & cis-Linalool oxide & 4.82 & 0.07 \\
\hline 12 & Terpinolene & 5.13 & 0.33 \\
\hline 13 & Linalool & 5.69 & 1.07 \\
\hline 14 & $\beta$-Terpineol & 6.59 & 0.07 \\
\hline 15 & Terpinen-4-ol & 7.32 & 0.72 \\
\hline 16 & Terpineol & $\mathbf{7 . 8 4}$ & $\mathbf{1 . 7 0}$ \\
\hline $\mathbf{1 7}$ & Estragole & $\mathbf{8 . 0 5}$ & $\mathbf{3 . 4 7}$ \\
\hline 18 & cis-Anethole & 9.43 & 1.31 \\
\hline 19 & trans-Anethole & $\mathbf{1 1 . 0 3}$ & $\mathbf{8 3 . 4 6}$ \\
\hline 20 & Eugenol & 12.62 & 0.24 \\
\hline 21 & Methyl anisate & 13.03 & 0.06 \\
\hline 22 & p-Methoxyphenylacetone & 13.35 & 0.37 \\
\hline 23 & p-Methoxypropiophenone & 14.95 & 0.05 \\
\hline 24 & cis-Methyl isoeugenol & 16.23 & 0.07 \\
\hline 25 & Acetyleugenol & 16.79 & 0.06 \\
\hline 26 & Nerolidol & 17.45 & 0.05 \\
\hline 27 & $\alpha-C a d i n o l$ & 18.76 & 0.04 \\
\hline 28 & Foeniculin & 19.35 & 0.27 \\
\hline
\end{tabular}




\subsection{Antibacterial activity}

In solid medium, the evaluation of the antibacterial activity of the essential oil of illicium verum is

determined by the measurement of the growth diameters in $\mathrm{mm}$ (figure1).

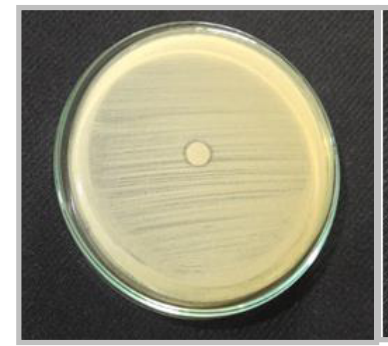

Staphylococcus aureus

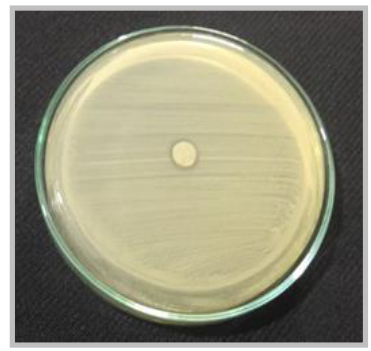

Staphylococcus epidermidis

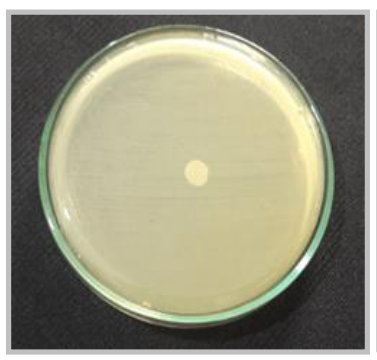

Acinetobacter baumannii

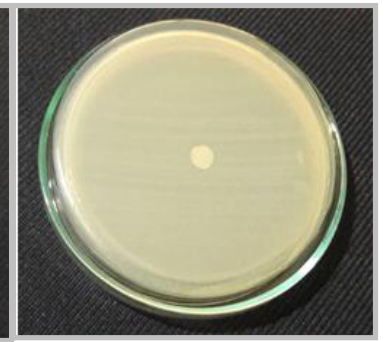

Escherichia Coli

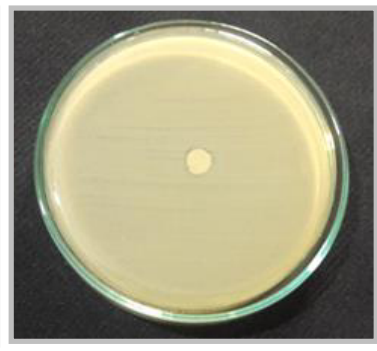

Klebsiella pneumoniae

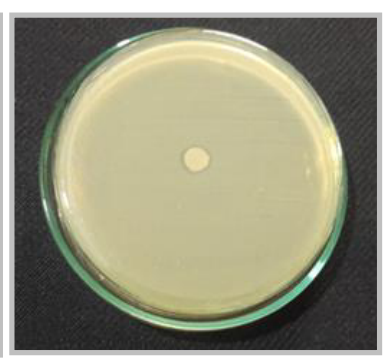

Enterobacter cloacae
Figure1. Antibacterial activity of essential oil against all bacterial strains tested.

The results for the different germs are presented in (Table 2 ). The results of the antibiogram test show a variation in the inhibition efficiency of the essential oil of Illicium verum against the tested bacterial strains. The considerable antibacterial effect was observed in comparison with the reference antibiotic against the strains of Staphylococcus aureus, Staphylococcus epidermidis and Enterobacter cloacae, with zones of inhibition in the order of $9.66,9.5$ and $9 \mathrm{~mm}$ respectively, whereas this essential oil did not show any effect on the bacterial strains of Klebsiella pneumoniae, Acinetobacter baumannii and Escherichia coli.
Table 2: Antibacterial activity of the essential oil of Illicium verum

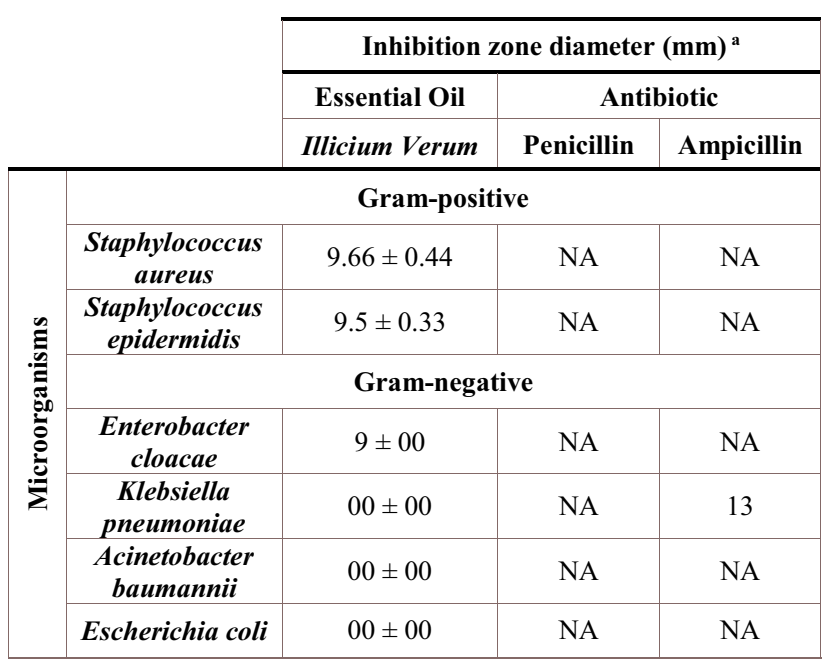

${ }^{a}$ Diameter of the inhibition zone including a disc diameter of $6 \mathrm{~mm}$, by the disc diffusion method at a concentration of $15 \mu$ of oil per disc and a concentration of 10 and $5 \mu \mathrm{g}$ per disc of ampicillin and penicillin, respectively.

NA: not active.

[32] Demonstrated that ethanolic extracts of Illicium verum induced substantial antibacterial activity against 67 drug-resistant clinical isolates, including 27 Acinetobacter baumannii, 20 Pseudomonas aeruginosa, and 20 meticillin-resistant Staphylococcus aureus. According to the study by [33] the essential oil of Illicium verum has an effect only on Escherichia coli strains. In another study, the antibacterial activity of absolute methanol extracts was significant with zones of inhibition ranging from 12 to $15 \mathrm{~mm}$ [34]. However, it is generally expected that the sensitivity of Gram-positive bacteria is higher than that of Gram-negative bacteria [35.36.] Yet, this is the case in the present study; Gram-positive bacteria (Staphylococcus aureus and Staphylococcus epidermidis) are sensitive compared to Gram-negative bacteria (Enterobacter cloacae, Klebsiella pneumoniae, Acinetobacter baumannii and Escherichia coli).

\subsection{MIC Determination}

Figure 2 and Table 3 show the MICs of Illicium Verum EO on strains with inhibition diameters greater than or equal to $8 \mathrm{~mm}$ [37]. The essential oil of Illicium Verum shows a very high antibacterial activity on Staphylococcus aureus with a MIC equal to $1 / 1000$ (v/v)), while the strains Staphylococcus epidermidis and Enterobacter cloacae has a significant activity with a MIC of about $1 / 100(\mathrm{v} / \mathrm{v})$. 
Table 3. Minimum inhibitory concentration (MIC) of essential oil Illicium Verum

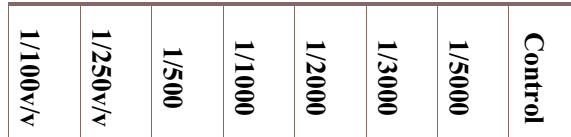

\begin{tabular}{|c|c|c|c|c|c|c|c|c|c|}
\hline \multirow{6}{*}{ 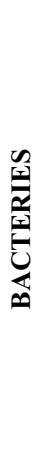 } & \multicolumn{9}{|c|}{ Gram-positive } \\
\hline & $\begin{array}{c}\text { Staphylococc } \\
\text { us aureus }\end{array}$ & - & - & - & - & + & + & + & + \\
\hline & $\begin{array}{l}\text { Staphylococc } \\
\text { us epidermidis }\end{array}$ & - & + & + & + & + & + & + & + \\
\hline & \multicolumn{9}{|c|}{ Gram-negative } \\
\hline & $\begin{array}{l}\text { Enterobacter } \\
\text { cloacae }\end{array}$ & - & + & + & + & + & + & + & + \\
\hline & (-): inhibition; & & & & & & & & \\
\hline
\end{tabular}

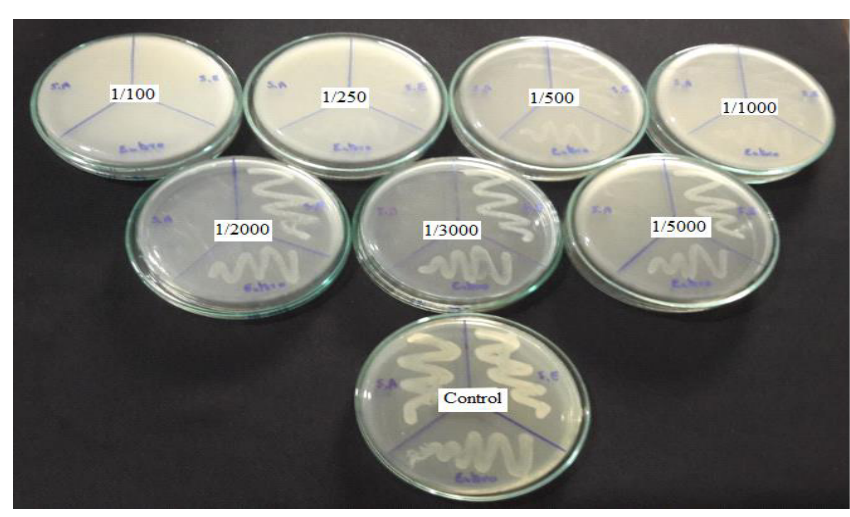

Figure 2. Minimum inhibitory concentration of Illicium Verum essential oil against three bacterial strains Staphylococcus aureus (S.A), Staphylococcus epidermidis (S.E) and Enterobacter cloacae (Entero).

According to the study by [33] MIC of star anise absolute methanol extract evaluated against $E$. coli $(15.6 \mathrm{mg} / \mathrm{ml})$ was higher against L.monocytogenes, $S$. arizona, and $S$. aureus $(7.8 \mathrm{mg} / \mathrm{ml}$ for each). In addition, MICs were similar for Gram-negative and Gram-positive bacteria and ranged from 7.8 to $31.2 \mathrm{mg} / \mathrm{ml}$. [38] found similar results using the agar well diffusion technique, with the antimicrobial activity of Illicium verum extracted using acetone showing significant inhibitory activity against Staphylococcus aureus. It was also reported that star anise essential oils were active against $S$. aureus and $E$. coli, but had no activity against Salmonella typhi [39].

The antimicrobial activity is attributed in particular to the anethole present in the dried fruit [38.40]. In addition, other components of star anise extracts, present in small amounts, could be considered for their potential synergistic and antagonistic properties [41]. The mode of action of E-anethole is not yet fully understood, but it has been suggested that the integrity of the bacterial membrane could be disrupted by lipophilic compounds th[32]. This hypothesis is supported by observations obtained from scanning electron microscopy analysis, where it was shown that the chemical components exerted their toxic effects against the tested strains by disrupting the integrity of the bacterial membrane. These ingredients were able to destroy cell integrity and thus inhibit respiration and iron transport processes. They could also increase the membrane permeability of bacterial mitochondria [42].

\subsection{Antioxidant activity}

The antioxidant power of the EO of Illicium Verum is carried out by the method of reduction of the DPPH radical. This antioxidant activity was expressed by the IC50 value which represents the concentration of Illicium Verum EO necessary to inhibit $50 \%$ of the DPPH- free radical. This concentration is calculated from the equation of the line shown in Figure 3.
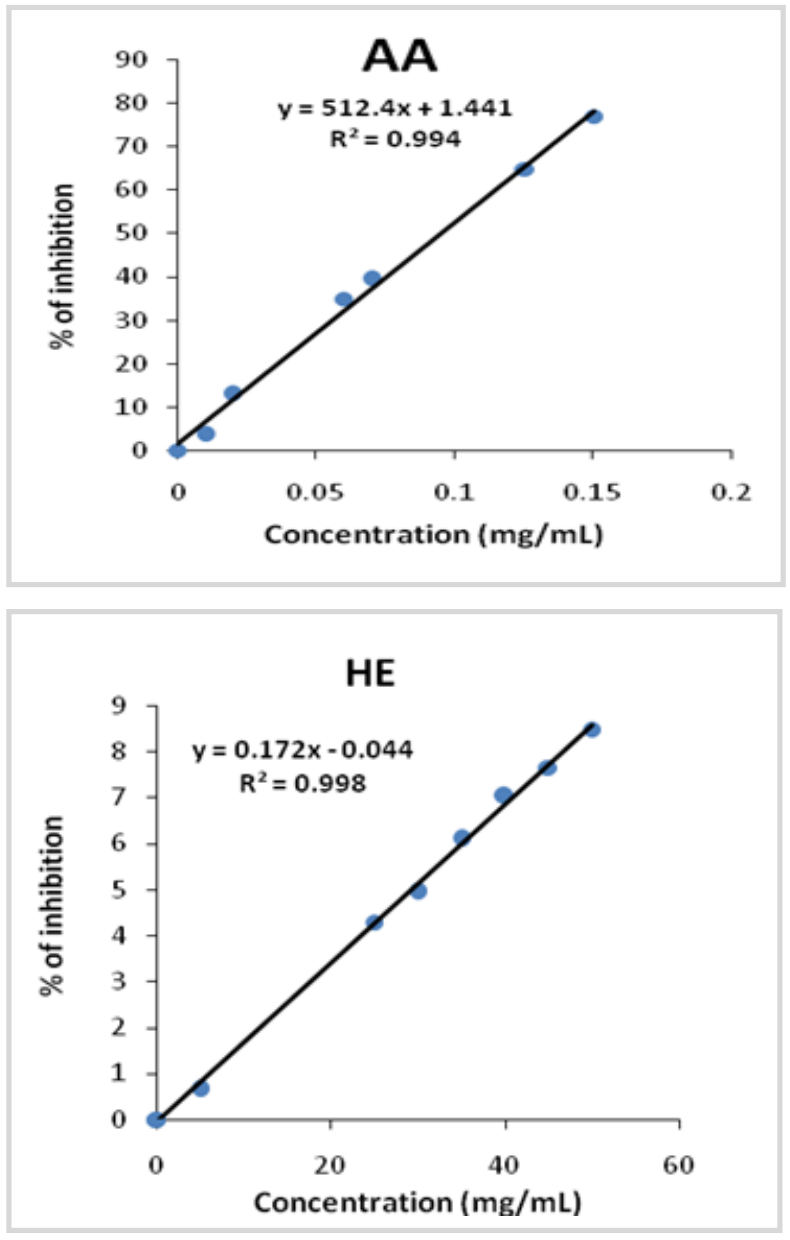

Figure 3: Antioxidant activity of Illicium Verum essential oil (HE) and ascorbic acid (AA).

A lower IC50 value indicates a higher antioxidant activity. Ascorbic acid is taken as the reference molecule and has the highest activity, with an IC50 value of about $0.09 \pm 0.01 \mathrm{mg} / \mathrm{ml}$. The essential oil of Illicium Verum showed lower antioxidant activity than ascorbic acid with an IC50 value of $286.19 \pm 7.4 \mathrm{mg} / \mathrm{mL}$. This result can be explained by the abundance of trans-anethole $(83.46 \%)$ in the chemical composition of Illicium Verum essential oil. A previous study showed that this compound has a low 
antioxidant activity compared to other phenolic compounds [43]. Other studies have also shown the low antioxidant activity of the essential oils of Foeniculum vulgare Muller and Pimpinella anisum, which are constituted mostly by trans-anethol, with a percentage of $77.6 \%$ and $94.2 \%$, respectively [44.45]

\section{Conclusion}

The essential oils of Illcium verum and its major constituents are natural aromatic compounds that are characterized by a broad spectrum of biological activities. The main objective of this work is to test the effectiveness of essential oils of Illcium verum as antibacterial and antioxidant against gram positive and negative bacteria and the determination of the chemical composition.

The results obtained in this work show that the essential oil has a medium sensitivity and the MIC is about $1 / 100$ and $1 / 1000$. For the antioxidant power the essential oil of Illcium verum is very inferior to that of ascorbic acid. On the other hand, the chemical composition of this oil shows a remarkable richness in active principle mainly transanethol $(83,46 \%)$

These results remain preliminary, so it would be interesting to continue the investigations on this fruit by focusing on other extracts or even isolation of substances that underlie the various activities detected. To better evaluate the anti-bacterial activity, other in Vitro and in Vivo studies would be interesting, and it would be desirable to make other pursuits in order to reveal the other biological activities of Illcium verum.

\section{Reference}

1. N. Gokoglu, J.Sc. Food. Agri, 99, 2068-2077 (2019)

2. J. Hassna, R. Ijoub, A. Oubihi, I. Ouryemchi, M. Chakit, B. Bourkhiss, M. Ouhssine, Am. J. innov. Res. Appl. Sci, 7, 186-190 (2018).

3. M. Bammou, EDT. Bouhlali, K. Sellam, J. bijbijen, L. EL Rhaffari L, L. Nassiri, Phytothérapie, 01-08, (2020)

4. A.K. Shakya, (2016). Medicinal plants: Future source of new drugs. International Journal of Herbal Medicine, 4(4), 59-64, (2016)

6. H. Talbi, A. Boumaza, K. El-mostafa, J. Talbi, A. Hilali, J. Mater and Environ Sci, 6,1111-1117 (2015)

6. O. HADJI, F. TARFAYA, Doctoral dissertation, Université Mohamed BOUDIAF de M'Sila. Algeria (2019)

7. L. McGaw, A. Jäger, O. Grace, C. Fennel, J. van Staden, Medicinal plants. In Ethics in AgricultureAn African Perspective, 67-83 (2005)

8. K. Traoré, M. Haidara, A. Denou, F. Kanadjigui, M.N. Sogoba, B. Diarra, S. Maiga, R. Sanogo, J. Eur. Sci, 15(6), 212-226 (2019)

9. J.P. Jaeg, Revue Méd Vét, 170(1-3), 22-33 (2019)
10. R. Boulamtat, A. Mesfioui, K. El-Fakhouri, A. Oubayoucef, A. Sabraoui, A. Aasfar, M. ElBouhssini, Crop Protection, 144, 105607 (2021)

11. J.K. Patra, G. Das, S. Bose, C.N. Vishnuprasad, M.D.P. Rodriguez-Torres, H.S. Shin, Phytotherapy Research, 1-20 (2020)

12. A. Dzamic, M. Sokovic, M. S. Ristic, S. GrijicJovanovic, J. Vukojevic, P.D. Marin, Chem. Nat. Compounds, 45(2), 259-261 (2019)

13. G.W. Wang, Hu WT, B.K. Huang, L.P. Qin. $J$ Ethnopharmacol, 136(1):10-20 (2011)

14. M. De, A. Krishna De, P. Sen, A.B. Banerjee, Phy. Res., 16: 94-95 (2002)

15. Y. Huang, J. Zhao, L. Zhou, J. Wang, Y. Gong, X. Chen, Z. Guo, Q. Wang, W. Jiang, Molecules, 15(11), 7558-7569 (2010)

16. H. Jaber, A. Oubihi, I. Ouryemchi, R. Boulamtat, A. Oubayoucef, B. Bourkhiss, M. Ouhssine, Biochem. Res. Int, (2021)

17. A. Oubihi, I. Ouryemchi, I. Nounah, K. Tarfaoui, H. Harhar, M. Ouhssine, Z. Guessous, Adv. Tradit. Med, 20, 673-679, (2020)

18. S. Haida, A. Kribii, South Afr. J. Bot, 131, 151-160 (2020)

19. A. Oubihi, H. HosnI, I. Nounah, A. Ettouil, H. Harhar, K. Alaoui, M. Ouhssine, Z. Guessous, Biochem. Res. Int, (2020)

20. S. Echeverrigaray, G. Agostini, L. Atti-Serfini, N. Paroul, G.F. Pauletti, A.C. Atti dos Santos, J. Agric. Food Chem. 49, 4220-4223 (2001)

21. N. Zayyad, A. Farah, J. Bahhou, Bull. Société R. Sci. Liège, 83, 118-132 (2014)

22. P.N. Nam, P.T. Kim Lien, T.T. Hoa, C.M. Huong, D. Thien, J Food Agric, 29,131-137 (2017)

23. A.K. Dwivedy, V.K. Singh, B. Prakash, N.K. Dubey, Food Chem Toxicol, 111:102/113 (2018)

24. A. Luís, S. Sousa, J. Wackerlig, D. Dobusch, A.P. Duarte, L. ereira, F. Domingues, Flavour and Fragrance Journal, 34(4), 260-270 (2019)

25. M. De, A. Krishna De, P. Sen, A.B. Banerjee, Phy. Res., 16: 94-95 (2002)

26. A. Luís, A. Duarte, J. Gominho, F. Domingues, A.P. Duarte, Ind Crops Prod, 79,274/282 (2016)

27. P.H.B. Cabral, R.M. Campos, M.C. Fonteles, C.F. Santos, J.H.L Cardoso, N.R.F. Nascimento, Life Sci, 112:74/81 (2014)

28. M. Brada, M. Bezzina, M. Marlier, A. Carlier, G. Lognay, Biotechnol Agron Soc Env, 5 (2007)

29. A. Jaafari, H.A. Mouse, E.M. Rakib, L.A. M'barek, M. Tilaoui, C. Benbakhta, A. Boulli, A. Abbad, A. Zyad, Rev. Bras. Farmacogn, 17 (2007)

30. R. Karousou, D.N. Koureas, S. Kokkini, Phytochemistry.66,2668-2673 (2005) 
31. A. Hajib, I. Nounah, A. Oubihi, H. Harhar, S. Gharby, B. Kartah, K. Bougrin, Z. Charrouf, J. Essent. Oil Bear. Plants1-10 (2020)

32. J.F. Yang, C.H. Yang, H.W. Chang, C.S. Yang, S.M. Wang, M.C. Hsieh, L.Y. Chuang, J. med food, 13(5), 1254-1262 (2010)

33. J.M. Freire, M.G. Cardoso, L.R. Batista, M.A. Andrade, Revista Brasileira de Plantas Medicinais, 13(2), 209-214 (2011)

34. M.S. Alhajj, M.A.A. Qasem, A.R. Jar El Nabi, S.I. Al Mufarrej, Brazilian Journal of Poultry Science, 21,001-008 (2019)

35. B. Shan, Y.Z. Cai, J.D. Brooks, H. Corke, International Journal of Food Microbiology, 117:112-119 (2007)

36. S.S.H. Mohamed, P.D. Hansi, T. Kavitha, International Journal of Pharmacology Sciences and Research, 1(10):430-434 (2010)

37. A.G. Ponce, R. Fritz, C. Del Valle, S.I. Roura, LWTFood Sci. Technol, 36, 679-684 (2003)

38. G. Singh, M.A. Sumitra, M.P. Lampasona, C. Catalan, J. Sc. Food. Agric, 86:111-121 (2006)

39. G. Singh, M. Sumitra, M. Palanisamy, H.S. Bawa, C.S.N. Indi, Journal of Natural Products and Resources, 6(2):114-121 (2007)

40. M. De, A. Krishna De, P. Sen, A.B. Banerjee, Phy. Res, 16: 94-95 (2002)

41. De M, Krishna De A, Sen P, A.B. Banerjee, Phy. Res, 16: 94-95 (2002)

42. J.S. Baik, K. Sang-Suk, L. Jung-A, O. Tae-Heon, K. Ji-Young, H.L. Nam, J. Microbio. Biotech, 18(1):74-79 (2008)

43. S. Freire Rosemayre, M. Morais Selene, A. Francisco Eduardo, Catunda-Junior, C.S.N. Pinheiro Diana, Bioorganic \& Medicinal Chemistry, 13(13),43534358 (2005)

44. P. Olivera, J. Mila, M. Mladen, Croatica Chemica Acta, 79 (4), 545-552, (2006).

45. S. Nanasombat, P. imuttigosol, Food Science and Biotechnology, 20(1), 45-53 (2011) 